\title{
Mapping the Technological Landscape to Accelerate Innovation
}

\author{
Jay Paap \\ President, jaypaap60@alum.mit.edu \\ Paap Associates, 351 Waban Avenue, Waban, MA, US
}

\begin{abstract}
$\mathrm{T}$ he quality of an innovative idea and the likelihood that it will lead to a successful new product or service is directly related to the quality of the information that is used to generate the idea and assess its value. Ideas based on a poor understanding of the underlying need or technologies that might be used to address that need will rarely succeed. An assessment of market attractiveness based on faulty estimates of customer readiness for your innovation and current or potential competitors' activities and their likely response to your offering is a high-risk effort. To successfully innovate, organizations need to have the best information possible to support their development efforts and up-to-date information on the eternal factors affecting an innovative project's success so they can decide whether it is worth continuing. Competitive Technical Intelligence (CTI) is a branch of Competitive Intelligence (CI) that provides those developing new technologies, products, and services the information required to make better project

selection decisions by ensuring the organization has the best information possible on customer needs, technology options (including using external collaborations to speed development and manage risk), and the competitive environment. CTI continues to provide value throughout the development process by alerting project managers to changes that might affect the attractiveness of a project under development. While CTI shares many tools and approaches with other forms of CI, it has special characteristics that call for a different way of managing the intelligence collection and analysis. Specifically, it is common to supplement the CTI staff's capabilities in ways not often found in other types of $\mathrm{CI}$ by leveraging the interest, knowledge, and skills of their users, the technical staff. Drawing on over half a century of research on technology forecasting and innovation, and several decades of the author's working with organizations to establish CTI programs, this article outlines where and how CTI can help organizations enhance their innovative efforts.
\end{abstract}

Keywords: innovation; competitive intelligence; competitive technical intelligence; scenarios; technology forecasting; project management; stage gate
Citation: Paap J. (2020) Mapping the Technological Landscape to Accelerate Innovation. Foresight and STI Governance, vol. 14, no 3, pp. 41-54. DOI: $10.17323 / 2500$ 2597.2020.3.41.54 


\section{Introduction}

As companies look to become more innovative, they need to address two questions:

- are we working on the right thing?

- are we doing the work correctly?

Many approaches to innovation address the first question by finding ways to quickly collect and screen ideas. They then spend most of their energy on exploring how to develop the best ideas they found. They develop sophisticated project management systems that focus on getting the project completed in a timely manner and explore ways to accelerate the development or manage risk through alliances, incubators, skunk works, and other alternative development paths.

These are indeed critical questions to address, and much of my innovation-focused work with organizations involves adjusting the culture, reward systems, development processes, and so forth in order to address the special challenges of developing innovative offerings.

Why do many of these attempts at innovation fail? Many mistakes are made, but one of the most common and most harmful is that too little time is spent on addressing the first challenge: working on the right thing. Organizations do a beautiful job of developing a product or service that is not worth developing. They start the process at the wrong point, seeking ideas rather than seeking information.

According to the oft-distorted version of Lord Chesterfield's classic advice: Whatever is not worth doing is not worth doing well.

\section{Innovation Starts with Information not Ideas}

If you conduct an online search for graphics of the term 'innovation' almost all resulting pictures will show it starting with a light bulb, since 'everyone knows' that innovation starts with ideas. However, innovation does not start with ideas, it starts with information. Ideas do not just appear; they are generated based on the information the person generating the idea (the idea generator) has about the nature of the need and the alternative technologies that might be used to meet that need. Unfortunately, most models of innovation fail to recognize this and start the process with a search for ideas. Why is this?

Part of the problem can be traced to the tremendous success and value of Bob Cooper's work on project management, the stage-gate ${ }^{\mathrm{pm}}$ approach to effectively getting from an idea to the marketplace [Cooper, 2011]. There is no question that such a phased or gated approach has improved many organizations' ability to successfully get new products and services to market. Unfortunately, his model starts with that ubiquitous light bulb, sufficient for managing projects in the pipeline, but not where you want to start planning for innovation. This image of the development process starting with an idea is so firmly ingrained in our psyche that we are lured into starting the innovation process with a search for ideas, an approach that significantly limits our ability to innovate and ignores important research on how ideas and innovation work.

An idea is one way to create information by connecting two or more pieces of existing information. If the connection is one no one has made before, it is a creative idea. The existing information may have come from scientists who discovered new materials, engineers who developed new tools or market researchers who uncovered new customer needs or market trends. Ideas play an important part in information, especially creative ideas. Without a creative idea, a product or service concept cannot be truly innovative, that is the first offering of a product or service that is purchased and used. In the new product/service development context, the idea links a need (or pain point, challenge, customer request, 'job to be done', outcome, etc.) and a technology (applied knowledge to find answers or solutions). In short, the quality of an idea is a function of the quality of the information upon which the idea generator draws when making their connections.

Thus, if you want to be more innovative you do not start by collecting ideas, you start by collecting the information that is behind good innovative ideas: on current and emerging customer needs, on current and emerging technologies that might address those needs, and on the STEEP factors (Sociological, Technical, Economical, Environmental, and Political) that shape the competitive environment in which potential customers will be assessing the attractiveness of your offering.

This is not a new insight. Project Sappho was a study done in the UK in the 1950s that pointed out the critical importance of good customer need information on the success of the innovative efforts they examined [Rothwell et al., 1974]. A study done at MIT in the 1960s by Meyers and Marquis to support the NASA Apollo program expanded upon this and added in the importance of technology information [Meyers, Marquis, 1969]. It found a very clear pattern for how successful innovative projects were developed (Figure 1). There are two key takeaways from this study:

- The innovation pipeline starts with information on needs and technology as the basis of innovative ideas

- Having stages or phases throughout the development effort provides an opportunity to reassess the value of continuing as you learn 
The last point is critical in understanding the full importance of CTI on innovation. While CTI can help you generate ideas that have the greatest potential for success by starting with good information, its value does not end there. As noted in the MIT study, gates are important places to reflect on the wisdom of continuing a project as new information is learned, both about the project progress and the attractiveness of the opportunity. This insight was operationalized by Cooper's Stage-Gate ${ }^{\mathrm{mm}}$ process which many organizations now use. However, too often organizations use their gates to ask but one question: "are we on plan?" This is likely sufficient for routine projects where there are few unknowns other than whether the project is proceeding as planned.

However, innovative projects involve doing something no one has done before and by their nature have a lot of uncertainty both about the attractiveness of the opportunity and the soundness of your approach. As you proceed, those uncertainties are usually resolved, sometimes favorably ('the market is bigger than we thought') and sometimes less so ('the technology does not work'). The fundamental question that Cooper asks you to answer at each of the gate reviews is not: "are we on plan?" but rather: "should we continue?" Answering that question requires that at each gate you consider updated information on the factors that were considered when launching the project.

In short, organizations need to recognize the critical role of timely intelligence on the factors that will determine whether a proposed innovative effort is worth pursuing, both when it is launched and as it is being developed. To enhance the chance of innovative success, organizations should develop a structured approach to collecting and analyzing information that will not only stimulate better ideas but provide the means for a mid-course correction (or killing) of projects as the world around them changes. That is the domain of Competitive Technical Intelligence (CTI) - intelligence that provides decision makers with the information based upon which to select what technology to use, how to acquire it, and how to best use it to develop or enhance innovative products and services.

\section{CTI Defined}

CTI is an organized approach to:

- Anticipate competitor's intentions.

- Anticipate new technologies.

- Anticipate changes in drivers

- Provide inputs for project selection, execution, and review.

CTI ensures that technical decisions are based upon the best available information, consistent with le- gal, ethical, and resource constraints. It helps those responsible for the front end of innovation have the information to create meaningful innovative ideas linking current and emerging customer needs with current and emerging technologies that can be used to address those needs (Figure 2).

It also helps through the development phase of the project by providing information to help scope the project and address problems that are encountered during development (Figure 3).

\section{CTI and Science and Technology Intelligence (STI)}

Science and Technology Intelligence (STI) is a major subset of CI that deals with developing intelligence on technology. It uses tools to assess patents, scientific literature, technical trade shows, and other sources of technical information to identify the who, where, why, and how fast new technologies are being developed or used. When editing a special issue of Competitive Intelligence Review [Paap, 1994] dealing with intelligence needed to support technical decisions, I wanted to differentiate the topic from STI and coined the phrase CTI. Much of the CI world divides itself into areas based on what is collected: financial intelligence, market intelligence, etc. CTI is not about the what, but who the intelligence is collected for, the technical manager tasked with identifying technologies that will allow them to develop the products and services that will meet their current and future customer's needs in a timely and competitive manner. CTI uses STI of course, but it also develops intelligence on customers, markets, competitors, and other external forces affecting decisions about what technologies might be needed to support an organization's innovative efforts. Since many practitioners now treat CTI as STI, intelligence about technology, the term Competitive Intelligence for Innovation $\left(\mathrm{CI}^{2}\right)$ is often used instead of CTI [Paap, 2018].

\section{CTI is Project-Based}

CTI is different than most traditional competitive intelligence (CI) efforts. The traditional approach to 'the CI cycle' was proposed by Jan Herring decades ago based on the approach used in the intelligence community (Figure 4). It is designed to support what Herring calls 'Key Intelligence Topics' (KITs) that are a subject of ongoing interest to the organization using the intelligence cycle outputs [Herring, 1999].

While some CTI activities fit this model, more often a one-time project-based approach is warranted. Rarely is there a need for ongoing collection and analysis of an area of interest. CTI follows more closely the principles of PMBOK - Project Management Book of Knowledge [PMI, 2017]. 


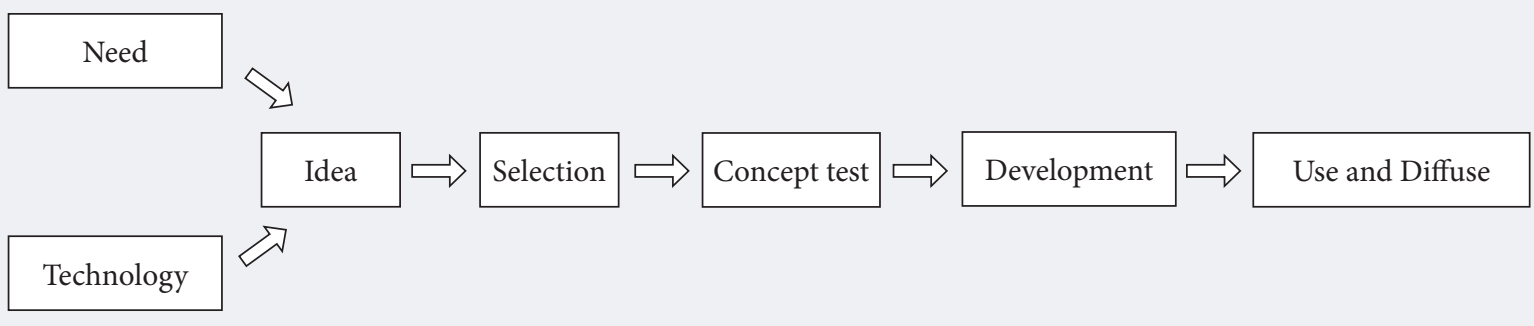

Source: adapted from [Meyers, Marquis, 1969].

While usually lacking the rigor of a PMBOK-based planning system, it shares the underlying logic of an activity with a specific start, finish, and internal reviews to refocus and or terminate. CTI is characterized by numerous 'one-off' intelligence efforts, such as:

- What is the impact of a new regulation upon customer needs?

- Who has a technology that can address this need?

- Is there a partner we should consider working with to accelerate development?

- Is this technology the right technology?

Having a project focus has several important implications for how the CTI effort is organized and managed. In traditional CI efforts where the focus is on a few KITs, the CI office typically is staffed with topic experts and much of their effort is focused upon building and using internal databases that they stock with relevant, up-to-date information on the companies, markets, or socioeconomic trends they are tasked with monitoring. It allows the CI staff to be able to quickly respond to intelligence requests, drawing on the information collected and stored on the target KITs. As needed, they supplement the existing information with additional collection and analysis of human source or external database derived information. CTI typically operates differently both in its use of databases and how it is staffed.

\section{Database Implications}

Over time CTI groups will develop intelligence that needs to be stored and retrieved and will usually have a database. However, unlike more traditional CI operations which continually update the KIT-focused intelligence inputs, the range of topics is too broad, and the frequency of looking at any individual area so spread out, that it is not practical to keep the database up-to-date. So, while the internal database can be used as a starting point for a project, there is more reliance on external sources (databases and patent mapping services) that are kept up-to-date by the service providers. Similarly, the use of supplemental intelligence collection through interviews, visits, or attendance at professional meetings plays a more significant role in CTI. Additionally, while traditional CI databases are often open to the organization at large as a resource when doing planning activities, access to CTI databases is usually limited to CI professionals who are aware that the intelligence may be out-of-date and should not be relied upon without updating.

\section{Staffing Implications}

CTI usually has too many possible areas of interest to justify having topic experts on staff. I was working with a major chemical and materials company helping set up new front-end planning and roadmapping processes. Separately they hired a consultant to design a CTI program for them. The chemical company had a diverse technical portfolio with a huge range of products ranging from commodities like fertilizer and basic chemicals, to more esoteric specialty chemicals and materials. The CI expert followed the script for staffing a CI organization with specialists in each of their major technical areas as well as specialists in online and human source collection. They recommended creating a CTI organization with over two dozen staff. This to support the development efforts of a 600 -person R\&D organization. It was a non-starter.

When they shared the report with me, I suggested they take a different approach. I had recently set up a CTI function at Shell's upstream research group that deviated from the established practice of creating an office full of subject matter experts. Shell's CTI office was very small (about half a dozen) and limited to those with expertise on data collection and analysis; technical topic expertise was drawn 


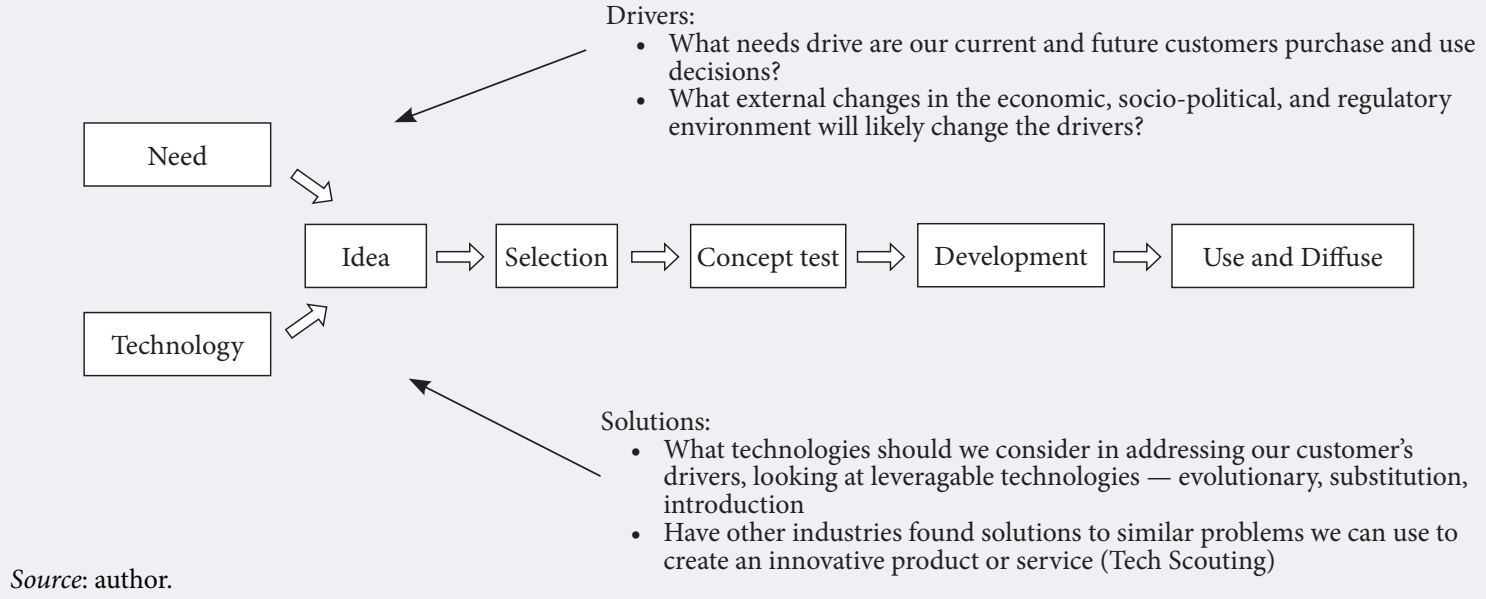

from the technical staff. When a project was begun, relevant technical staff were part of the planning. They helped identify the terms that might be used in online searches, the companies or universities that had expertise in an area and might be worth talking to, the professional associations that operated in their area, and similar information that could help focus the collection effort. Note: often internal technical experts have an inflated view of their level of expertise and when asked who they would suggest talking to, who was working on different technologies, their answer would often be: "no one, we have that covered." A better way to leverage your experts' insights into external activities is to ask who they knew of who is wasting their time working on an alternative (and inferior) technology to theirs.

At Shell we also set up training programs for project managers, involving several hundred staff over the first two years. This was a new approach for them. Shell's scenario planning, Game Changer, and other futures thinking programs were (and are) amongst the best in the world. What we did here was to push some of this expertise down to those doing the project work. Project managers learned how to recognize when external intelligence could improve their project planning and thus become more frequent users of CTI. They learned how to frame a meaningful intelligence question to focus the search so that they were both more efficient themselves, but when they needed additional

\section{Figure 3. CTI and project execution}

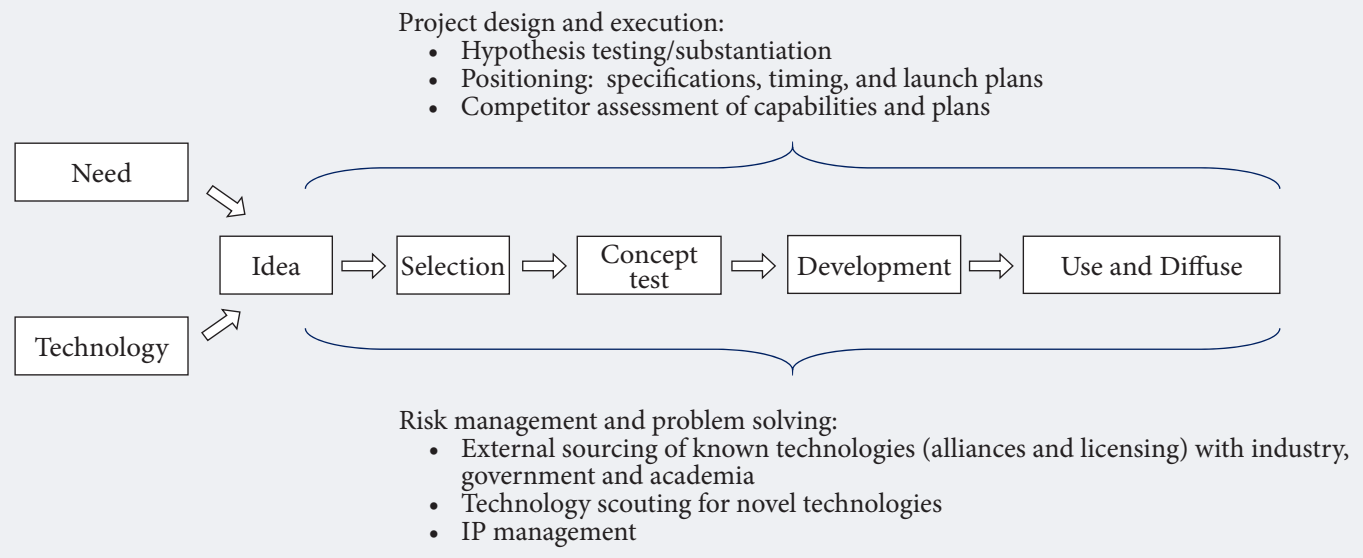

Source: author. 


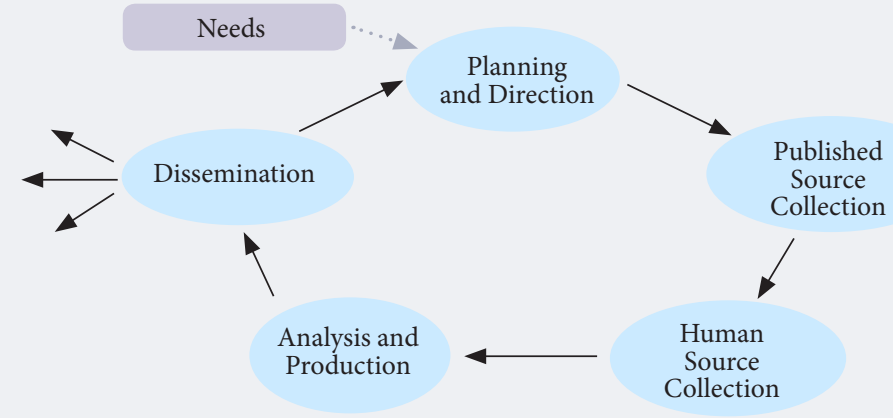

Traditional ongoing CI cycle

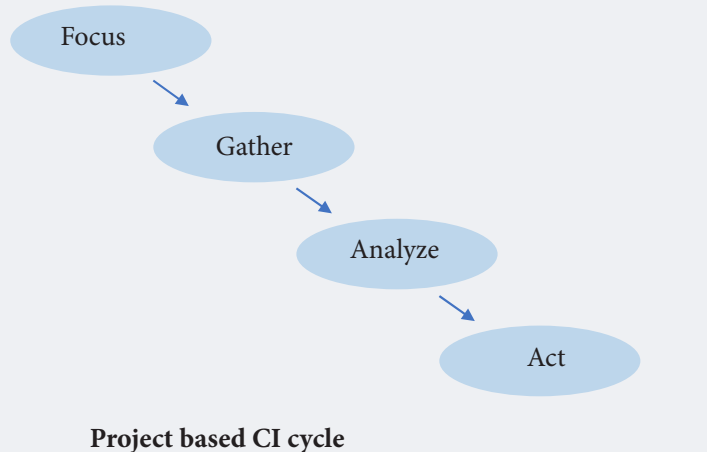

Source: [Herring, 1999].

help, the CTI staff could respond more quickly. Project managers were given tools to do online searches more efficiently and trained in basic interviewing techniques to collect intelligence at professional meetings. Did they have the skills that a trained CI professional would have? Of course not. But they could now do many of the day-to-day collection and analysis tasks well enough that the CTI staff could focus on the more challenging intelligence questions. More importantly, the technical staff were already doing online searches, reading patents, talking to former professors, and interacting with colleagues at professional meetings. They could now do these tasks more effectively. The use of technical staff is an especially powerful way to collect CTI information at trade shows as they have the contacts and context to facilitate the efficient collection and assessment [Paap, 2007]. Additionally, the training raised the technical staff's awareness of the counterintelligence challenges of talking to others and thus made them less likely to share sensitive information with others outside of Shell.

\section{What to Look for: NOMMAR ${ }^{\mathrm{rm}}$}

Exactly what types of information should CTI look for? There are many models outlining the information needed to generate and support innovative concepts. One I have found very powerful was developed during a multi-company roundtable I chaired in the mid-1990s. We called ourselves the Commercialization Roundtable and were made up of senior managers from nine major organizations responsible for promoting innovative new development efforts. The companies involved were AT\&T, Digital Equipment, Dow, DuPont, GTE (now Verizon), IBM, MCC, Motorola, and Xerox. We met every month or two over 18 months to share our experiences in developing and commercializing innovative products and services. One of the areas looked at was the information needed to develop and validate an innovative concept. While each or- ganization used slightly different terms, there was an underlying theme that emerged covering six factors that can be summarized as NOMMAR ${ }^{\mathrm{TM}}$ :

- Need - is there information that indicates there is or will be a significant unmet customer need?

- Option - will a technology be available that could successfully address that need?

- Market - is there a market for that approach, considering competitive offerings, its cost, and the operational or organizational changes that the innovative product or service might require the customer to make?

- Model - is there a business model that convincingly outlines how it can be profitably developed, produced, and supported?

- Approach - is there an approach available to our organization that is likely to allow us to successfully address the market?

- Relevance - if it can be done, should it; is it relevant to our overall strategy?

The first four questions combine information the company has internally with intelligence collected by its CTI team on activities outside the organization. Information on needs and technology options is used to stimulate ideas. Information on needs, options, the market readiness and size, and business models is used to assess the potential attractiveness of the opportunity.

The last two questions are answered primarily with information the company has internally to determine whether it is possible and relevant. However, CTI can often help with identifying a workable approach by identifying potential partners.

These questions are asked when first assessing a project, using the information CTI provides, and they are asked again at each gate using updated information provided by the CTI activity. 


\section{CTI Tools}

It is beyond the scope of this article to go into depth on all of the tools that CTI uses. In the following section I will outline a few tools that I find most useful, focusing primarily on those used to answer the first two NOMMAR ${ }^{\text {ti }}$ questions, as these are the ones most critical in helping generate meaningful innovative ideas.

\section{Needs}

The key to anticipating disruptive innovations is to anticipate changes in the needs that drive your customer's purchase and use decisions [Paap, Katz, 2004]. There are a host of tools that can be useful in identifying needs: traditional market research, consumer research, voice of the customer visits to current and potential customers, observation of your customer (popular with Design Thinking planning models (see e.g. [Kelley, 2016]), and emerging uses of social media and big data to find underlying patterns of behavior that help anticipate customer needs. For example, Amazon has patented and is using a system it calls 'predictive shipping' to use cumulative data collected on the habits of its customers to anticipate with a high degree of accuracy that a shopper will order a product in the near future so that they can move the product to a closer warehouse to the shopper's home ahead of the order and thus cut down on shipping time [Natale, 2019]. Most of these use interactions with customers to understand their current needs states or pain points and are effective in generating ideas for incremental improvements. They are less effective at anticipating future needs that exist but are not yet salient enough to affect your customers' behavior, or do not exist now but are likely to emerge as your customer's situation changes.

There are three tools that I find effective in anticipating future customer needs, needs that your current or future customers may or may not know they will have: technology forecasting, scenarios, and lead user assessment.

\section{Technology Forecasting}

I will cover technology forecast in more detail later as it is a primary tool used in the identification of alternative technologies that can be used to address customer needs. However, there is a role for tech forecasting in anticipating needs. Dick Davis was Manager of Technology Forecasting and Technology assessment at Whirlpool from 1968 to 1975. He was a student and colleague of Jim Bright, often recognized as the father of modern technology forecasting (e.g., [Bright, 1968, 1969; Bright, Schoeman, 1973]). Davis started one of the first professional CI practices at an industrial company, the Whirlpool Information Network (WIN) in the late 1960s and his futures-based CI work helped guide both the strategy and product development efforts at Whirlpool.

I worked with Dick after he retired from Whirlpool and learned much of my forecasting and CI skills from him. One of his favorite tools was technology forecasting. Not just on the technology that was needed to build their products. He did that of course, looking at control systems, power supplies, agitators, motors, and the like to ensure that Whirlpool was aware of the latest technology that might help them build better washing machines. However, one of his biggest successes at Whirlpool was using technology forecasting to anticipate needs their customers would have in the future based on changes in the technologies affecting their use of the washing machine, for example, water, detergent, fabric, and energy. He monitored technical developments in those areas and then assessed how these new technologies might change customer needs or priorities.

He learned of new developments in the fabric area where firms were working on wash and wear materials made of polyester and cotton blends that would reduce the need to iron (a major unmet need). Dick talked to the firms developing them and learned that changes in the wash cycle were needed for them to work well. Working with washing machine designers Whirlpool retooled their washing machines to work with the new fabrics well before the fabrics were introduced. Additionally, market studies had shown that one reason Whirlpool was not selling a dryer with every washer was that cotton bedsheets and garments from a dryer took longer to iron when a consumer used a dryer than if allowed to air dry. Reflecting on the implications of the new technology, he forecast that there would likely be an increased demand on dryers once bedsheets were made with the new blend that would emerge wrinkle free from a dryer with a cool down cycle. He convinced Whirlpool not only to add a cool down feature, but to expand its dryer capacity. As a result, once the new fabrics were introduced, Whirlpool was the only white goods manufacturer prepared to meet the new demands and Whirlpool's market share of washers increased significantly, and the sales of dryers exploded [ $D a$ vis, 1973].

\section{Scenarios}

Tech forecasting is really a specialized version of scenarios. While scenarios have been around for decades, I have seen an increased interest in their use over the last five to 10 years. Scenarios are useful when your development cycle extends beyond the time frame that existing customer/consumer behavior models provide reliable information, and/ or when technology is moving at increasingly rap- 
id rates. As the world changes ever more quickly, companies are finding that even the near future is uncertain. When the future is uncertain, scenarios can help.

Many firms have a major misconception about scenarios, they believe that scenarios are tools to predict the future. Scenarios do not 'predict' the future; they identify multiple probable futures and provide a basis for understanding the implications of each of those possible futures on their business so they can prepare for it.

A recent scenario exercise outlines how useful they can be in helping to focus longer term development efforts, where longer term is defined not by the length of the effort but by when the development's impact will be felt. In 2018, a major energy company was looking to identify the early stage developments they would need to position their organization for future energy requirements $40-50$ years out. Three scenarios sessions were held with about two dozen participants in each, with staff from research, sales, operations, and strategy. Prior to the session they were sent reports from various futures groups identifying mega trends and reports from market research and research trade groups identifying possible futures. At each session, the participants took turns identifying what they thought the world of 2050 would be like, drawing on their own experience, interaction with customers and colleagues, and reflecting upon the forecasts they were given. In each session common themes emerged that identified the core dimensions upon which the participants described the possible future. These were abstracted and possible positions on each were identified and the implications for customer needs and operations were identified.

The most likely combinations of the different dimensions were used to develop a picture of several future worlds that collectively represented most of the demands the company might be asked to meet. The next step was to identify what technical capabilities would be needed to address each of the future scenarios. As usually happens, a few technology families were identified as essential regardless of which possible future actually happened. This provided strong validation to begin planning for how the organization could develop or acquire those capabilities. Others were likely needed in only a couple of the futures. This led to two activities. First, competitive intelligence monitoring to get an early indication of whether one of those futures might occur. Second, the organization launched several initiatives to monitor and participate in developments in these less likely technologies using alliances, consortia, or university collaborations. The goal was to develop a starting point if and when it was determined they might be needed.
There are two historical examples that highlight how others have used this approach. IBM's work on the PC was a low-level affair for many years as they monitored the hobby computer market (TRS80, Atari, Commodore, Sinclair, Apple, etc.). They did not believe that a business would ever need or buy a small computer, but their corporate goal was to offer any size computer a business might want. Once a business bought a small computer, they wanted to be ready to launch a comparable offering as soon as possible. When small businesses started buying VisiCalc for the Apple II, they moved the nascent development to Boca Raton, added staff, and launched the PC in record time. Much has been written about how IBM was able to develop the PC in record time due to a different structure (an internal venture), changes in project management approaches, and the like. All of these were critical in launching the PC. However, an important contributing factor was that they anticipated the possible (although they thought improbable) customer need for a small computer and prepared to move if required.

One last example is from Astra Zeneca's Project Orion [Rosenkranz, 2003]. Wayne Rosenkranz, who was a strategy and CI executive in their advanced development group, had a scenario session exactly as described in the first example. They used the results to justify the development of several new technologies that Astra Zeneca lacked in 2003 but would be needed if they hoped to be successful in twenty years, regardless of the future.

When we think of scenarios, we often think of looking out 20 to 40 years as in the examples cited above. However, the time is a function of the dynamics of your industry and the volatility and predictability of customer behavior and market conditions. A scenario session I participated in with a snack and cereal company looked three to four years out, well beyond the company's comfort level of knowing what to expect.

\section{The Technology Paradox}

The Technology Paradox is a challenge that organizations routinely face as the rate of change of the world around them continues to accelerate. It occurs when a technology they depend upon appears to be maturing and there is pressure to find and invest in the technology that will replace it. The challenge is that often the old technology has not reached its limits and pressure from competing technologies spurs innovative efforts to keep it alive and relevant. Consider the demise predicted in the mid-1980s for magnetic storage when optical storage first emerged. The threat from optical spurred innovation that kept magnetic storage

\footnotetext{
${ }^{3}$ The scenario exercises were part of a larger consulting assignment Dr. Paap undertook with the energy company as part of their long term planning effort..
} 
alive for several more decades. A bigger challenge is that even if the old technology is in fact mature and due for replacement, there rarely is a single pretender to the throne, multiple technology alternatives emerge to replace the old technology.

This is the paradox: if we invest in all the new technologies while maintaining investment in the old technology (that might rebound) we will go broke. If we sit back and wait to see which one will emerge and begin development after it is obvious, we will be too late. Two practices can help manage the paradox. The one most often cited is the use of external collaborations as part of your development strategy. Corporate Venturing, as it was known from the early 1970s through the turn of the century [Paap, 1990], or Open Innovation as it is more often referred to today [Chesbrough, 2006], can help organizations address the technology paradox by enabling smaller bets on multiple alternative technologies through alliances, consortia, or internal ventures (as IBM did with the PC), and provide a return on the investment in developments they determine were not needed through spin-offs [Paap, 1991]. CTI is the second tool. It can provide an early read on possible futures and an early indication of which option is likely to win, and information on potential partners or spin-off buyers in support of collaborative development efforts.

\section{Lead User}

Lead user is an approach to uncovering customer needs and solutions based upon the existence in several industries of customers who develop solutions to needs they have that are not shared by a large enough segment of a company's target market to justify their working on them. Eric von Hippel at MIT has several decades of case studies of major innovations that were first developed by frustrated users whose developments came to the attention of larger firms who recognized that others also had or would have the need and they could adapt the lead user's approach. He cites the development of the first heart lung machine in the garage of a frustrated doctor who tired of losing patients because there was not enough time to do the surgery when the patient's heart was stopped, or the farmer in the Midwest who cobbled together pipe and wheels from his barn to make the first circular irrigation system to more efficiently irrigate his fields [von Hippel, 2011]. Figure 5 describes the underlying logic. First someone addresses a need they have that is too small for larger organizations to pay attention to. These are often picked up through social media, chat rooms, or websites in which similar potential innovation-inclined users are involved. If the need is widely felt, these other users adopt and often improve the solutions of the original lead user in what von Hippel calls user communities.
Activity there is eventually noticed by larger firms (the Producers) who adapt the innovation for the larger markets they are interested in.

CTI can look for people addressing needs they have that are not yet broadly recognized by roaming chat rooms and looking through sites targeted at potential customers. Their target customers may eventually have the need, or always had and now recognize it, and the market could be large enough to interest larger product and service providers. By routinely visiting sites where users share their problems and solutions, they can often get a head start on a new innovative offering.

Some lead users keep the innovation to themselves. To uncover these, CTI teams can visit current customers to see how they have adapted or modified existing equipment or software. They may have a need you are unaware of, modified your product to address it, and there may be others who share that need. One way to view customers who use your product or service in ways that it was not designed for is that they are not misusing your product, they are telling you what they need. I recall engineers in the first consulting firm I worked in the early 1970s who broke into their Wang Word Processor and added code so that it could handle payroll and other personnel tasks. Wang never realized there was a need for a small computer, they made word processors. These had all the components of a minicomputer, just dedicated to the single task of word processing. Had they visited some of their more sophisticated users, they might have seen them modifying their machines and recognized these were customers who were letting them know about an unmet need they could easily address by modifying their equipment for others. Such an insight might have changed the fortunes of Wang.

\section{Technology Options}

While not its primary focus, CTI also looks for technologies. There are literally dozens of technology forecasting techniques. Probably the best inventory of tools I have found comes from John Vanston, another student of Jim Bright who describes the uses of more than 25 of them [Vanston, 2003]. I will look at three techniques not in the Vanston listing: Analogous Problem Exploration (APE), patent analysis, and crowd sourcing.

APE. The search for technology options is not just confined to forecasting the emergence of new technologies. Innovation does not necessarily involve either a new technology or a new need. What makes an idea creative is that it is a new connection. While it might be linking a new technology to a new or existing need, it might also tie an old technology to a new or old need. Too often the search for innovative technical information focuses on finding the newest 'disruptive' or 'breakthrough' 
technology. Of course, organizations should learn about new technologies, but they also should learn about existing technologies used in other applications that might be newly applied to their needs. The goal is not to use the latest technology but to know about the latest technologies, other existing technologies, and then to use the right technology.

One tool that is useful in finding old technologies to consider when attempting to address your customer's need is a subset of technology scouting: Analogous Problem Exploration (APE). It is similar in logic to the TRIZ approach to creative problem solving [Altshuller, 1996]. Figure 6 shows the underlying logic.

The approach is quite straightforward. You take the need or problem you have, identify others that have a similar need, learn how they addressed that need, and consider using it yourself. There are two classic examples of this approach in James Burke's fascinating book on the origins of the building blocks for major innovations, Connections [Burke, 2007]. When the French were building the first internal combustion engines, they adapted the technology first used in perfume atomizers. The atomizer makers had developed expertise in the physics of combining air and liquids, and the machine tooling to create precision nozzles that would provide a uniform mixture. This is exactly what was needed to make carburetors. When Hollerith convinced the US government to use his idea of punch cards to process census data in the 1890 s, he did not develop the card reader from scratch. He identified others who had a similar challenge and adapted bank's money counting machines as the first card sorters [Hollerith, 1894]. A visit to the US Mint in Washington DC will show that the size of the ubiquitous IBM punch card, which was the main way of feeding information into early mainframes and is still used by airlines and car rental firms, just happens to be the same size as US currency in 1890 . He made his punch card the size of the currency so he could use the money counters.

In a CTI project for an oil exploration firm a few years ago. we used this approach to find technology that could be used to help process noisy seismic soundings used to map oil reserves. Who else had technology to extract meaningful information from millions of pieces of noisy data? The answer was a company started by former NASA engineers who had worked on analyzing noisy data from space probes.

The key when looking for new technology is not to look for organizations that have a technology you know about, but to look for companies that share your problems and needs who may be using a technology you were unaware of or had never considered using in the way they are doing. Find organizations that face the challenges you face and learn from them. Too often technology scouting is used only after an idea has been generated as a tool to find someone who has a missing piece of your solution, scouting is a gap filling process. This is basically just a fancy form of procurement. CTI and scouting can have a much greater impact upon innovation by enlarging your awareness of the possible technologies that might be used to address a customer's need. It collects information before ideas are generated to increase the probability of having truly innovative ideas.

Patent analysis has been a basic tool of CTI for decades [Ashton, 1993; Ashton, Klavans, 1997]. It can help you identify who the players are, new developments in a particular technical area, and many sophisticated patent mapping programs can provide insights on development trends. Patent citation analysis can give insights into those patents that actually influence the developments in a particular field.

There are two areas where I find patent information can help innovation beyond their use in looking at

Figure 5. The Lead user as a source of customer needs and innovative solutions

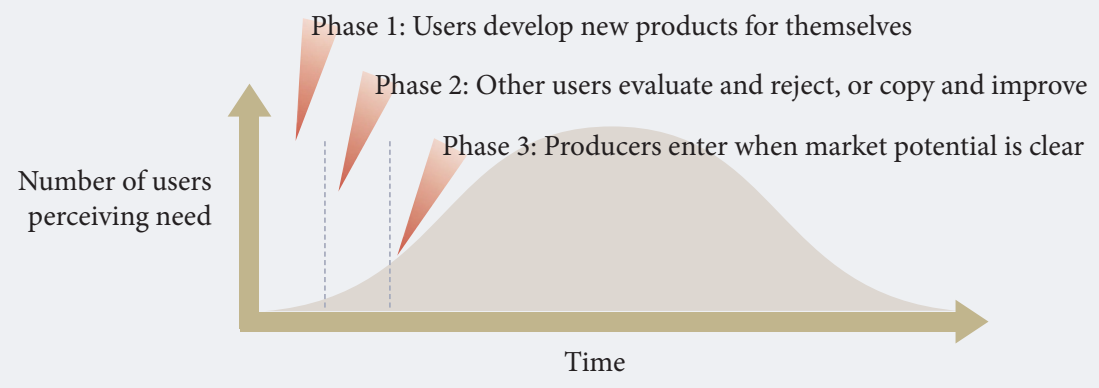

Source: [Von Hippel, 2011]. 


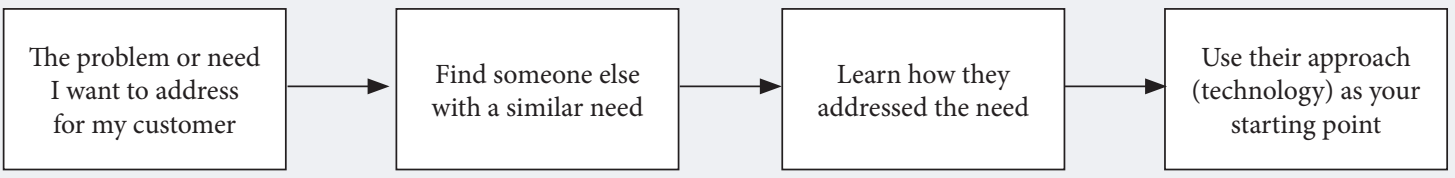

Source: author.

new technology, development trends, and players. Patents can also focus human source intelligence by identifying the scientists and engineers who are at the forefront of their field. Patents tell you about what was done ' $x$ ' years ago. Those involved can often tell you what the current state of the art is. Reviewing their papers or talks or interviewing them can often give insights into what is coming next. Second, as patent mapping software has become more sophisticated it allows for a variation on the APE approach using patents. Increasingly patent search engines are using text mining to enable a search beyond predescribed data points and with the right algorithms it is possible to search for the types of problems a patent is addressing, not just a search on the keywords or technologies used.

Crowd sourcing is an oft-misunderstood term. Large numbers of people, crowds, generally have more noise than meaningful information. The key is to identify a subset of the crowd, a tribe or community, who have knowledge and insights worth tapping into and who you can trust with sharing your problem. Once you identify this community, you can solicit their ideas on how to develop solutions to needs that you or your customers have. Several public and internal platforms exist and when managed well can be a way of learning about new technologies.

On the surface, these platforms look like a traditional idea bank but there is something richer going on. As mentioned earlier, an idea is merely the combination of two or more pieces of information: a need with a technology to address that need. Figure 7 shows what is really going on when an idea is generated and submitted.

A participant in the community sees the need and draws on the technologies they know of that might be used to address it. They make a connection and an idea is generated which they submit. There are often hundreds of participants in the community so in effect you are tapping into hundreds of dif- ferent repositories of technical knowledge. The implications for screening submissions are that the focus is as much on the technology the submitter used as the idea itself.

The experience of one government organization shows how effective this approach can be. Started in the early part of this decade, about a dozen government agencies who shared common goals created a platform to post challenges and request inputs from several thousand of their employees. Few submission requests were posted as originally written. Most challenges were attempts to find out how to implement the solution the submitter had come up with for meeting their underlying need, thus limiting the ways to address the need to variations of their approach. The request was re-written to indicate the underlying need and then a sponsor was found. One of the major insights about customer behavior is that not all of their needs are ones that if met will lead to your customer buying that solution [Paap, Katz, 2004]. They may have more important unmet needs they will work on satisfying first. It is basically Maslow's need hierarchy at work: you meet more important needs before you will spend time working on less important ones [Maslow, 1954]. A need's leverage refers to it being a need that a customer is sufficiently unhappy with that they are willing to do something to make it better. To ensure that all posted needs had leverage, a sponsor was identified who had both the interest and resources to implement the solution if one was found.

The submissions were examined not only for the solution itself, but also to explore whether the technology being suggested might be used differently to solve the problem better than was suggested. Often, two or more technological approaches from different submitters were combined. The focus was on learning about alternative technologies, not in screening ideas.

The results were impressive. At a 2015 meeting of representatives of the participating organizations it 


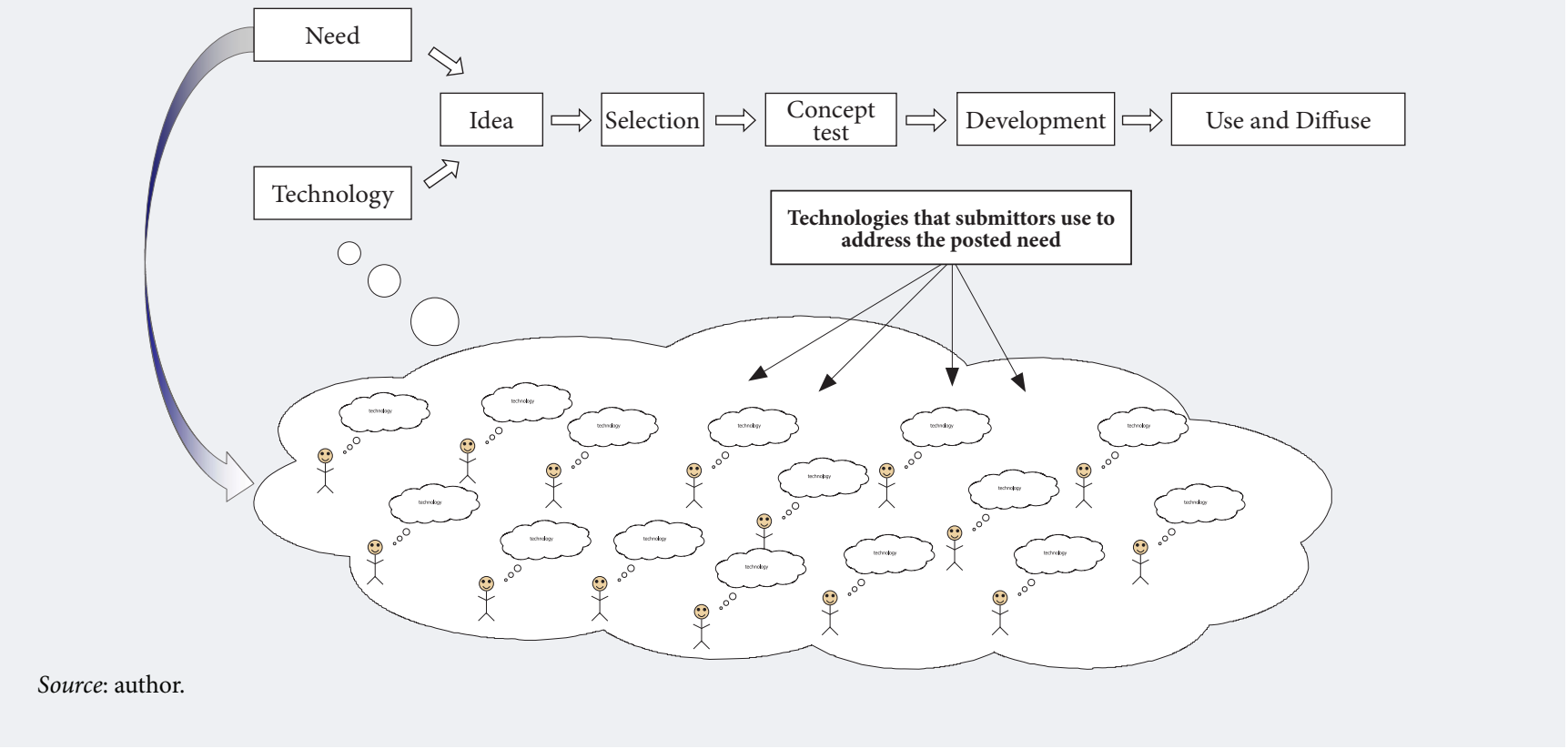

was reported that over $90 \%$ of the posted needs had been resolved and solutions implemented. The key was only posting high leverage needs and learning about technology options from among the member organizations.

\section{The Rest of NOMMAR}

To answer the remaining NOMMAR questions (Market, Model, Approach, and Relevance), CTI starts to look a lot like more traditional business and market CI. As a result, many CTI programs develop close relationships with the strategic and marketing CI groups to tap into their intelligence pools. The full range of intelligence collection tools are used to provide insights on the forces shaping the market and the attractiveness of your idea. CTI together with CI can help identify such things as:

- The size and readiness of a market.

- How competitors might react to your offering.

- What are others developing that might lure your target market from your offering?

- What business models have been used in similar ventures?

- Firms that might be available to partner as part of your approach.

Many of the traditional market assessment tools are limited in that they require that the customer being surveyed or questioned understands their needs (not always true) and appreciates the new offering (rarely true if it is truly innovative). So, the assessment often is done by finding analogues, other products, or services that had a similar genesis, and learning from them.

\section{Conclusions}

The reason Competitive Technical Intelligence (CTI) is so critical is based on the understanding that innovation starts with information, not ideas. Thus, organizations that desire to be more innovative need to spend significant time on efforts to gather and assess information as a prelude to idea screening and selection and continue to look for changes that might affect project success throughout the execution phase. CTI provides a structured approach to anticipate the future and acquire the information required to generate innovative ideas and effectively manage their development. CTI is usually managed differently than traditional CI using a project as opposed to ongoing process model, and heavily involves the customer in the focusing, collection, and assessing of the intelligence product. Drawing on a wide range of CI tools, both from science and technology (STI) and more traditional market and competitive intelligence, CTI provides timely intelligence to decision makers on the forces that will determine the eventual success of their development efforts. 


\section{References}

Altshuller G. (1996) And Suddenly the Inventor Appeared: TRIZ, the Theory of Inventive Problem Solving, Worcester, MA: Technical Innovation Center, Inc.

Ashton W.B., Sen R. (1988) Using Patent Information in Technology Business Planning. Research-Technology Management, vol. 31, no 6, pp. 42-46.

Ashton W.B., Klavans R.A. (1997) Keeping Abreast of Science and Technology: Technical Intelligence for Business, Columbus, OH: Battelle Press.

Bright J.R. (1969) Some management lessons from technological innovation research. Long Range Planning, vol. 2, no 1, pp. 36-41.

Bright J.R., Schoeman M.E.F. (eds.) (1973) A Practical Guide to Technological Forecasting, Englewood Cliffs, NJ: Prentice Hall.

Bright J.R. (1968) Technological forecasting for industry and government, Englewood Cliffs, NJ: Prentice Hall.

Burke J. (2007) Connections, New York: Simon \& Schuster.

Chesbrough H.W. (2006) Open Innovation: The New Imperative for Creating and Profiting from Technology, Brighton, MA: Harvard Business Review Press.

Cooper R.G. (2011) Winning at New Products ( $4^{\text {th }}$ ed.), New York: Basic Books.

Davis R.C. (1973) Organizing and Conducting Technological Forecasting in a Consumer Goods Firm. A Practical Guide to Technological Forecasting (eds. J.R. Bright, M.E.F. Schoeman), Englewood Cliffs, NJ: Prentice Hall, pp. 601-618.

Herring J. (1999) Key Intelligence Topics: A Process to Identify and Define Intelligence Needs. Competitive Intelligence Review, vol. 10, no 2, pp. 4-14.

Hollerith H. (1894) The Electric Tabulating Machine. Journal of the Royal Statistical Society, vol. 57, no 4, pp. 678-682. DOI: 10.2307/2979610.

Kelley T. (2016) The Art of Innovation: Lessons in Creativity from IDEO, London: Profile Books.

Maslow A.H. (1954) Motivation and Personality, New York: Harper \& Row.

Meyers S., Marquis D.G. (1969) Successful Industrial Innovation, Washington, D.C.: National Science Foundation.

Natale S. (2019) Amazon Can Read Your Mind: A Media Archaeology of the Algorithmic Imaginary. Believing in Bits: Digital Media and the Supernatural (eds. S. Natale, D.W. Pasulka), Oxford: Oxford University Press, pp. 19-36.

Paap J., Katz R. (2004) Anticipating Disruptive Innovation. Research-Technology Management, vol. 47, no 5, pp. 13-22.

Paap J. (1990) A Venture Capitalists Advice for Successful Strategic Alliances. Planning Review, vol. 18, no 5, pp. 20-22.

Paap J. (2018) Competitive Intelligence for Innovation. Paper presented at the Martec Executive Workshop, Shanghai, China, June 26-27, 2018.

Paap J. (2007) Competitive Technical Intelligence at Trade Shows and Professional Meetings. Conference and Trade Show Intelligence (eds. B. Hohhof, J. Calof), Alexandria, VA: Competitive Intelligence Foundation, pp. 177-191.

Paap J. (1991) The VC Opportunity in Corporate Spinoffs. Venture Capital Journal, vol. 30, no 12.

Paap J. (1994) Technology management and competitive intelligence: New techniques for a changing world. Competitive Intelligence Review, vol. 5, no 1, pp. 2-4. 
PMI (2017) A Guide to the Project Management Body of Knowledge (PMBOK ${ }^{\circledast}$ Guide) (6th ed.), Newtown Square, PA: Project Management Institute.

Roberts E.B. (1988) Managing Invention and Innovation: What We've Learned. Research-Technology Management, vol. 31, no 1, pp. 11-29.

Rosenkranz W. (2003) Continuous Scenarioing and Strategic Early Warning in Pharmaceuticals. Paper presented at the SCIP 2003 International Conference, March 12-15, 2003, Anaheim, California.

Rothwell R., Freeman C., Horsley A., Jervis V.T.P., Robertson A.B., Freeman J. (1974) SAPPHO updated-project SAPPHO phase II. Research Policy, vol. 3, no 3, pp. 258-291.

Vanston J.H. (2003) Better Forecasts, Better Plans, Better Results. Research-Technology Management, vol. 46, no 1, pp. 47-58.

von Hippel E. (2011) The User Innovation Revolution. MIT Sloan Management Review, Fall, Reprint no 53107. Available at: https://sloanreview.mit.edu/article/the-user-innovation-revolution/, accessed 18.05.2020. 